\title{
Leadership for Learning: Tasks of Learning Culture
}

\author{
Joe Corrigan \\ Doctoral Student, 7-104, Education Policy Studies, Faculty of Education \\ University of Alberta, Edmonton, Alberta T6G2G5, Canada \\ E-mail: joe.corrigan@ualberta.ca
}

Received: March 10, 2012

Accepted: March 21, 2012 Online Published: May 17, 2012

doi:10.5539/hes.v2n2p155

URL: http://dx.doi.org/10.5539/hes.v2n2p155

\begin{abstract}
This is a comparative analysis of leadership related to organizational culture and change that occurred at a large Canadian university during a twenty year period 1983 - 2003. From an institutional development perspective, leadership is characterized as a culture creation and development responsibility. By centering on the tasks of learning culture, this case study compared the challenge of leadership in two very different and competing organizational contexts. Using an experiential narrative and Constructionist approach, this research builds upon the work of Schein. This approach offers pragmatic insight into concepts such as trust and psychological safety that are often abstracted and ambiguous within organizational theory.
\end{abstract}

Keywords: Leadership, Learning culture, Higher education, Culture, Canadian universities

\section{Leadership for Learning: Tasks of Learning Culture}

The purpose of this case study review is to ask what leadership behaviours contributed to the creation of a learning culture in this comparative study of two organizations. This is an analysis of organizational culture change that occurred when an international education project split-off from a large Canadian university in 1993, and became a not-for-profit organization owned by a consortium of private and public sector interests. It centers on selected actions taken by the organizational Founder to embed learning as a priority within organizational culture during the first years of operation. The observations included here originate in my role as an employee of both the old and new organization, and my experience of both the institutional culture and the culture of the fledgling organization. Using Schein's (2010) criteria for developing organizations where learning will flourish, the way selected artifacts, beliefs, and assumptions of leadership become operational within the new organization are explored. By using this example as a tool for reflecting upon socially embedded knowledge valuation processes, practitioners may consider how their own assumptions about leadership may constrain or support learning. This paper locates the specific tasks of learning culture in a time of economic expansion, and individual readers must critically assess the extent to which this experience offers comment on their own operational context. Finally, in the Constructionist approach used in this analysis, cultural developers will be reminded of the extent to which communication, individual reciprocal relationships of trust, and value alignment with organizational objectives foster and support learning.

\section{Theoretical Perspective}

This article was developed within a series of assumptions about the nature of reality and what constitutes knowledge. A legacy of positivism suggests there are objective forms of inquiry, or science, based upon one knowable reality (Kincheloe, 2004). While this has been a dominant paradigm of inquiry, it is not the approach taken here, and I suggest it is not the most suitable research framework for understanding complex social processes. Instead, a Constructionist theory of knowledge guides this inquiry and locates learning as a social process - something that happens between people. This view asserts "all knowledge, and therefore all meaningful reality as such, is contingent upon human practices, being constructed in and out of interaction between human beings and their world, and developed and transmitted within an essentially social context” (Crotty, 1998, p. 42). The social location of knowledge has important implications for learning within organizations, and it underlines the importance of individual perspectives and meaning-making in dynamic support and opposition to organizational objectives (Argyris, 1959). It has substantial implications for the inclusion and exclusion of diverse individual perspectives from ideologies that are dominant within organizations, including the systemic alienation of women from masculine occupational culture (Biklen, Marshall \& Pollard, 2008). To adopt a Constructionist theoretical perspective and 
embrace Constructivist methods is to insist upon recognition and welcoming of the plurality of worldviews that are to be found in a heterogeneous organization.

\subsection{Method}

A particularistic case study as described by Merriam (1998; 2002) will provide a contextualized understanding and Constructivist location for analysis of this case. Care has been taken to select a case based upon a bounded system that will serve as both the unit of analysis and a local site where multi-vocal meanings can be identified and differentiated. This researcher has been the primary instrument of data collection, developing meaning and understanding through experience. In undertaking this kind of study, there is a substantial amount of interpretation at work, inviting the researcher to influence the outcome of the inquiry through articulated and unarticulated bias. For this reason, this research will be conducted within a notion of validity that has been re-framed according to a criterion for interpretive accounts that includes coherence and meaning in relation to future contexts (Packer \& Addison, 1989). The anonymity of all individuals and organizations described here is an ethical consideration complementary to the case method and conducive to candid analysis.

\subsection{Terms}

Situating this case requires the operational definition of terms such as organization, organizational culture, learning culture and leadership so they may be explored in a common framework of understanding and analysis. However, the first and primary challenge is to embrace a Constructivist worldview that holds "what exists is in significant measure dependent upon the mind that knows it" (Greenfield, 1980, p. 42). Understandably then, this paper rejects a conventional understanding of organizations as buildings, organizational charts and policy manuals, and instead uses Greenfield's (1979) conception of organization as an "ideological invention of the human mind-as invented social reality" (p.100). In this discussion, "organizations are cultures rather than structures and it is the maintenance and contestation of what is to constitute the culture of organizational life that provides the dynamic of rationality, legitimization and motivation in organization” (Bates, 1982, p. 9). The tradition of reifying organizations has worked against an understanding of organizations as cultures, and yet the positioning of organizations as cultures is a precondition for better understanding how organizations may create conditions where learning and the co-creation of knowledge is possible.

The characteristics of learning culture and leadership are made explicit here according to their role within organizations, however, these are highly contested terms and it is recognized their use will take on different meanings in differing contexts. Schein (1999) defined culture as a "pattern of shared tacit assumptions that was learned by a group...considered valid and, therefore, to be taught to new members as the correct way to perceive, think, and feel in relation to those problems" (p. 27). Schein (2010) argued learning culture acts on several beliefs, including active problem solving and a commitment to the learning process, faith in people, and trust the external environment(s) can be managed. From this perspective, learning is a shared and future oriented activity, where there is a commitment to integrating diverse worldviews, systemic thinking and reflective cultural analysis. Schein proposed perception and insight, motivation, emotional strength, awareness of and ability to change cultural assumptions and involvement or participation as the characteristics of leadership required to develop learning culture. Schein (2009) also discussed in detail the importance and culturally embedded meanings that permeate the offering, receiving and giving of help, a capability of importance in the increasingly fragmented and specialized roles of contemporary organizations.

For the sake of discussion and analysis, it will be useful to clarify some terms to better describe and understand organizational culture. Schein (2010) identifies three levels of culture, with the deepest level being (1) assumptions, or the "unconscious, and taken-for-granted beliefs and values" (p. 24). The middle level consists of (2) espoused beliefs and values. The most visible - yet difficult to decipher, are the (3) artifacts that consist of linguistic and other structures, processes and observed behaviour. Although described as distinct levels, they are understood here as highly interactive and reinforcing elements that promote stability and consistency in the worldview of individuals operating within micro-culture. In this view, organizations themselves mediate and generate individual and group cultural understandings, at the same time they operate within larger meso and macro-cultures. Individuals do not adopt cultural insider status quickly, and the following conditions of observation (Boostrom, 1994) are used to differentiate between levels of cultural immersion and participation. The result is a multi-layered series of inter-related cultural and ideological beliefs and understandings that help us to be cultural operators moving seamlessly between family and friends, organizations, and other roles within our lives.

\section{Skunkworks: A Case Study}

The Skunkworks began as a series of international projects at a large Canadian university between 1983 and 1992, and then became a separate not-for-profit organization offering international services and operating under a 
stakeholder Board of Directors. I will first describe the early institutional (1983-1986) origins of the new organization, and then contrast the latter institutional (1986-1992) culture with the learning culture growing in the new organization. Skunkworks was selected as the name of this case study to demarcate the creative counter-institutional culture that permeated the approach being taken to international projects within this group. During those early years, my involvement was primarily a series of summer jobs while an undergraduate at the same institution, and my work centered on the simple work of hosting international delegates, such as making coffee, meeting people at the airport and photocopying. The leaders of these projects were mature graduate students or early career professionals working on contract for the institution, and they had a substantial amount of international experience informing their ideas and project management practice. This was an exciting and fun place for me to work, but there were beginning to be indications our working group was out of cultural synchronization with the larger institutional culture.

\subsection{Latter Institutional Phase}

During the latter institutional (1986-1992) phase, I became an insider to the Skunkworks culture, as I joined the working group full-time and began taking on projects of my own under the guidance of more experienced peers. However, there was an increasing frequency and intensity of uncomfortable surface conflicts between the rule and procedure oriented institutional culture and Skunkworks project culture. A hard-working and highly-regarded Director did not have his contract renewed, and the institution seemed to have difficulty tolerating the project culture - except for the notable exception of the revenue stream created by Skunkworks projects. An 'us against them' dynamic surfaced in small and large ways, and the following example may bring that image into sharper focus. On an occasion when I had two international delegates arriving late one evening, I did what myself and others in the Skunkworks group who did not own cars had done many times before, I signed-out a marked van from the vehicle pool to pick-up the guests at our international airport. (This was a routine event, but nevertheless an episode that has stuck with me for many years.)

Several days later, I was summoned to the office of an important person within the institutional culture, and although the 'invitation' was a bit cryptic - I had no reason for concern or anxiety, and I cheerfully presumed it would be a routine meeting of some sort. Apparently, a receptionist had seen me driving the vehicle after hours, and written a widely circulated memo that included the word joy-riding in it. Although I cannot say I remember too much from that most sombre of meetings all those years ago, there was institutional incredulity that I was not chastened or embarrassed about my actions. Even after my polite - but unapologetic explanation, the administrator representing the institutional culture involved asked me several different times why I was meeting these people at the airport, and all that I could offer at that time was a vague rationale - it seemed like the thing to do.

Today, I understand that from a Skunkworks perspective, the practice of personal welcoming and caretaking of visitors - especially from Asia, was seen as a basic first-step in developing a reciprocal and values-based relationship. The unspoken assumption was the human relationship being developed superseded whatever exchange we might be taking part in at the moment. Put another way, the cultural assumption being operationalized was to reduce the transactional nature of the particular exchange and recognize it as part of a broader relationship with our guests that would unfold in the decades - not weeks - to come. In this context, learning the names of your guests' children has a different meaning, it changes from polite small-talk where useful data is exchanged to - the real, and pleasant prospect of meeting them in future. I never saw the joy-riding memo - but its alleged content grew to epic and improbably humorous proportions in the speculative imagination of my peers at the Skunkworks, and it became one of many issues that rallied and divided us from the larger and dominant institutional culture.

\subsection{New Organization}

The birth phase of the new organization $(1993$ - 2003) was dominated by the Founder whose first job was to negotiate separation from the institution, and maintain or grow revenue streams so the new organization would be self-supporting. The Founder was an individual with exceptional talent, commitment, and ability, and someone who had served in a variety of prestigious post-secondary administrative roles across Canada. By then, myself and one other person were the only people from the old working group remaining and that wished to join the new organization. We each had our respective baptisms of fire before we could join the organization, and this involved keeping-up to the Founder on highly intensive project work for an extended period of time. On these intensive project work experiences there was a tightly observed impartiality of practice and ideas that did not observe position or educational status. With only three individuals in the organization, and the other two having considerably more academic and international experience than myself, I was keenly aware and appreciative of this working situation. There was also an unspoken message communicating you can do it however you want, as long as you have met our basic organizational needs - and the related human relationships have been positively developed or extended. The 
operating procedure was that there were no procedures, and you were accountable for the results of your decisions, but unless you asked - no one was going to tell you how - or at times, even what to do. The following story may help to illustrate the new operational culture.

Despite operating on the limited revenues our programs would attract, an important source of pride in the new organization was customization and program enrichment for international courses and program participants. In addition to the Founder being adamant about the quality of instruction and educational experience within the programs offered, a high value was placed upon identifying and responding to individual and subgroup interests beyond the standard program framework. In one memorable example, the Founder asked me to meet with an instructor who was a candidate to present a course in an exceptionally obscure technical area for a new client in a country where we had not previously worked. The words to me were something like, 'the instructor looks ok to me, but I would like a second opinion, go to nearby city X and meet, and let me know what you think.' A few days later, and after a pleasant meeting and lunch with the prospective instructor, I phoned the Founder and said I thought the interviewee would do an excellent job. About three months later the program went ahead, and afterwards, representatives from the country in which it took place expressed mild dissatisfaction with the content, and low satisfaction with the instructor who had been condescending and disdainful of offered hospitality. The Founder located a new instructor - expanded the length of the course, and then offered it again to the client for free. It was an exceptional - and an absolutely unheard of thing to do at the time. The Founder never said a word to me or anyone else about the first instructor - there was no need - the second offering of the course had become an artifact within our organization and to other clients that clearly articulated organizational beliefs. The following are three related discussions of the case, including: (1) immersion within culture, the (2) Founder of the new organization, and the (3) tasks of learning culture.

\section{Analysis: Immersion in Culture}

The purpose of revisiting these events is to gain insight into the work of creating learning culture in organizations. Even so, it is also worth mentioning the events described (1983 - 2003) here, were taking place within the context of an innovative and growing global communications infrastructure, and a pervasive multi-faceted process of globalization. The prospects and possibilities of international education were expanding during this period, and post-secondary institutions were caught in a politics of what role the university should have within international education. Those who wished to preserve the traditional culture and operational style of post-secondary institutions did not welcome this new international program activity. They saw the revenues created by the new activity as feeding into a governance strategy of under-funding post-secondary institutions. These revenues would transform their own cherished institutions into ideological lapdogs of governments and multilateral agencies beholden to business and political interests. The Skunkworks group was working counter to the early or latter institutional culture (1983-1992), and saw great possibility for international education projects - and we were not as concerned about the compromises or consequences that might be involved. I needed a job, and the opportunity to work with people from all over the World was much more interesting than driving a forklift or working at a lumberyard in my hometown. Before an analysis of learning culture based on the Skunkworks case, it will be useful to comment briefly on each phase of work experience during the transition to the new organization.

During the early institutional (1983-1986) stage of this work, I was an outsider, an evaluator or subjective inquirer into the organizational culture, equivalent to stage three or four of six possible conditions of observation described by Boostrom (1994). My knowledge of the organization was fragmented or incomplete, and it was acquired through sporadic interaction of intensive project activity. The Director had been successful in creating an oasis of operations infused by assumptions and articulated beliefs that were counter to the dominant institutional culture. However, when these assumptions and beliefs came into conflict with the dominant culture - especially in visible ways, the dogmatic normativity (systems, procedures) of the institutional culture was consistently victorious. Even so, for an inexperienced undergraduate, involvement with the Skunkworks group was a compelling proposition when compared to the hierarchy of the institutional culture, which was based at that time upon educational attainment, specialization, international experience and linguistic ability. I was aware of certain differences between the institutional culture, and those articulated and assumed by the Director, but it was not possible for me to decipher the meaning of artifacts and cultural ritual associated with the Skunkworks activity at that time.

During the latter institutional (1986-1992) stage of my work experience, I became an insider, a cultural operator equivalent to stage five of six possible conditions of observation described by Boostrom (1994). My understanding of the Skunkworks culture had become relatively comprehensive, and I was able to participate authentically from a position within a growing us-against-them cultural perspective. My own interpretation of surface events began to develop - although slowly, and my understanding transformed into a conviction that our subgroup position was the correct one. I became a proponent and reproducer of the Skunkworks culture, and it was possible for me to 
recognize differences in assumptions between the two cultural approaches on my own. Today, I interpret the derisive speculation accorded to what may or may not have been included in the joy-riding memo as a mechanism employed to reduce apprehension and anxiety resulting from operating in conflict with the dominant and legitimized institutional culture.

During the 1993-2003 birth phase of the new organization, I slowly became a reflective interpreter of the early and latter institutional phases of my work experience, equivalent to a stage six condition of observation described by Boostrom (1994). At the same time, I was learning a new and transcending culture through my immersion in the working challenges of the new organization. In the new organization, I progressed quickly through the first four stages to become an insider (stage five) because of the project momentum from my previous experiences, and the intensity of working together with only two other individuals in an industrial office area. This was also a result of the consultation process reflected in the necessity of new beginnings, where computer systems, accounting software, letterhead, website, office lease, phones, and a sense of accountability to the other two individuals was a critical part of becoming productive and developing a collegial work environment.

During this phase, the Founder brought in topic specialists as resource people to facilitate half or full day out-of-office retreats on a variety of areas that were important to the future success of the organization. During this phase, areas of collective responsibility were distributed by the Founder to whoever had some experience or knowledge of what needed to be done. More important than the content of any one decision were the meetings held around a small round table - the only piece of furniture that was not in full use. A meeting at the table meant some new or important project, a decision needed to be made, or we had to find a collective way to tackle a new challenge. My understandings of the unspoken rules of those meetings are from a reflective interpreter (stage six) perspective and they are described more fully in the next section which introduces the individual most responsible for bringing learning culture to the new organization.

\subsection{Analysis: Founder of New Organization}

The Founder of the new organization had the self-confidence and determination of other founders described by Schein (2010). After the hierarchical approach characteristic of the institutional culture, the egalitarian accountability infusing the new organization was inspiring and perceived of as an opportunity for myself and one other junior member of the organization. Although there was a high level of informal communication around any matter related to project or other daily work of the organization, there were particularly important values enacted at round table meetings. These values attached priority to any relevant information related to the subject under discussion - regardless of the source. Although the Founder was the conduit to the Board, no major decision at the organizational level would be made until at least the three of us found a way to agree on a way forward together. If an agreement could not be reached however, allowing the issue that required attention to fester was also not an acceptable option. New ideas, approaches or ways of doing things were received and responded to according to the merit they represented as evaluated by the other two individuals. It was acceptable to withhold agreement for good reason, and the objections of one individual often reshaped - for the better - our organizational approach to a particular problem. This formulation of culture within the office setting may or may not have been unusual, but what made it exceptional and memorable for me was the consistency and egalitarianism with which these same values were enacted in the field on international projects, where much of the stress and strain of our project work occurred.

While it might be said the new organization was self-interested based upon our reliance upon revenues from project work to pay our salaries, bills and office lease, it must also be said another primary motivator was to work in an organizational culture where the unique experience of designing and managing international education projects was celebrated. This meant a lot of time in the field driving and caretaking program instructors and participants. It is also where the Founder insisted upon an undifferentiated role in project work. From the beginning, it was clear the Founder would be contributing a full share of all field work and that was particularly important during the first three years (1993-1995), when we could not afford to hire anyone else. However, it was also the Founder's rejection of a hierarchical claim to preferred assignments or allocation of blame if things went wrong in the field that anchored those values and commitments. It also provided an informed basis of experience from which instructional capacities and limitations, supplier relationships and learner experiences could knowledgeably be discussed and debated. Although the following example of embedding culture does not depend upon it for meaning, it was also not possible for us to miss the numerous prestigious invitations the Founder often received to give presentations, consult or serve on various boards.

The Founder offered to help support a project by setting-up a program enrichment activity I had identified with the local office of a national organization. It was scheduled for the end of a long day, and it was towards the end of a gruelling program with a medium to high-maintenance learner group. We were both excited by the innovative 
possibilities and the strong learning fit this early evening activity might have for the larger program. We spoke on the phone during the day and when asked if I had the address, I assured the Founder that I did. When I arrived 20 minutes late at the local office of the national organization - with my tired - but eager international learners, I was surprised not to see the Founder already there. When I called, the Founder answered a cellular phone and calmly told me the national President, regional Director and selected other executives were all ready and prepared to go ahead - and would we be there soon? I informed the Founder that I was at the office. The Founder then asked me what address I was calling from, and it became clear the organization had two offices in the same city. The event had to be cancelled because of the logistics associated with timing and transportation, and I was embarrassed - even angry with myself - for the miscommunication and inconvenience to our would-be hosts and Founder. However, from an organizational culture perspective, it was a shared-responsibility incident we both knew could have easily been prevented by more complete communication. It was already absolutely clear that each of us had been providing a best effort, and the meaning of the event might actually be reduced by its articulation. Today, I would summarize it as a reflection of the unarticulated belief that even when you have applied your best effort, mistakes will be made and everyone makes them. This is the presence of what Schein (1999; 2010) refers to as psychological safety, and it is a fundamentally important characteristic of organizational culture if learning is to take place.

\subsection{Analysis: Tasks of Learning Culture}

What did the Founder do to create a culture in which people would learn? One of the most powerful things the Founder did was to present real and unvarnished problems to others and then delegate authority for responding to it. Another was to identify a vision, and then let people find their own way towards the vision. In this way, the future of the new organization became a problem-based learning curriculum for cultural operators, but with some important differences. First, the new organization was not operating in opposition to a firmly established dominant culture, such as the one described earlier in the latter institutional phase (1986-1992). Second, the commitment to learning in the new organization was reinforced by the practical need to earn a living within a viable new organization. From this perspective, it was an energized and high commitment environment. Third, although we were young and relatively inexperienced, the Founder assumed we were capable of meeting important organizational challenges, and provided opportunities to demonstrate our ability. Schein (2010) referred to these positive assumptions about human nature as being Theory $Y$. In these observations and the preceding discussion, foundational elements of learning culture have been detailed through examples and discussion. Yet, these notions of self-efficacy, commitment and assumptions about human nature sound like they are stuck in academic and philosophical orientations to learning, rather than practical advice to cultural developers and creators of learning within organizations. What are some of the additional and concrete measures the Founder implemented to embed learning culture within the new organization?

In addition to favouring a professional development strategy based upon group needs, as favoured by Levin (2008), the Founder distributed organizational growth and development mandates (and related resources) as a shared responsibility to learn. In many organizations at that time - only senior people would travel to distant work locations. But by entrusting us with this shared responsibility, and using geographic divisions for program growth and development assignments without specifying how they should be achieved, three vastly different program inventories emerged in the three growth target regions of operation. These distinct approaches resulted from the application of effort from three individuals that had different education and experience, and who applied themselves in different ways to the same growth challenge in three separate geographic locations. The result was that programs and activities in one region looked very different from the programs and activities in either one of the other two regions. The organization appeared to be the same in all three regions because of a common visual identity practice, but the cultures and needs that defined these people and places were completely different. This aided the new organization by broadening the spectrum of programs, activities and services it was capable of performing, and with few exceptions, instructors, strategies and ideas were traded freely between regions. Later, growth and pressure for growth made this a more complicated proposition, but that was not until after 2003.

The Founder led with an intellectual confidence and security that welcomed new knowledge and alternative perspectives related to new and existing challenges - and changed direction when it was necessary. By avoiding ascribed status privilege and working through ideas as a group on their merit, the Founder modelled the creation of learning culture. That stance also discouraged others from standing on privilege later when others joined the new organization. It also had practical dividends for operations, as widely sought after instructors were not successful in rebuffing regional managers by going directly to the Founder for more favourable terms or conditions. As importantly, this organizational culture provided a confidential learning space where sensitive personnel or contractual information could be shared with one another before making new commitments. My experience of both sharing and receiving this type of information was that it was protected by a culturally well-defined and ethical 
commitment. Given this immersion into learning culture and learning culture leadership as modelled by the Founder, what further can be said about the tasks of learning culture?

These discussions have focused on the immersion, embedding and tasks of learning culture, without an analysis of the external environment, and how the dynamics of internal and external factors might influence the development of learning culture. However, it is worth comparing the external challenges of the Director whose contract was not renewed in the latter institutional phase (1986-1992), with the Founder's (1993-2003) experience in considering how the external environment might impact internal dynamics. For example, would the us-against-them polarization characteristic of the latter institutional phase support the growth of learning culture within the Skunkworks? Or, if the latter institutional phase can be characterized as lacking psychological safety because it was operating in opposition to the dominant institutional culture, then perhaps this dynamic was detrimental to the establishment of learning culture. The national reputation and profile the Founder brought into the learning culture creator role mostly prevented external actors (board members, other stakeholders) from interfering with internal dynamics. Did that protective umbrella represent an operational crutch for the learning culture that was established, and would that leave the organization vulnerable when the Founder eventually left the organization? Finally, given the important influence of external factors such as technological innovation in communication, broad-based growth in spending on international education, and an emerging globalization during this period, one might question to what extent did internal dynamics - such as the creation of a learning culture, significantly impact the growth trajectory of the organization?

\section{Findings}

The Skunkworks case follows the leadership story of a counter-dominant organizational culture that transitions from an institutional location to a new start-up culture. The Founder is able to create a learning culture through a high level of ability and commitment, and possibly through an ability to manage the external environment in a way that would avoid distractions. The Director whose contract was not renewed also had a high level of ability and commitment, but was not able to safeguard the subgroup from a disruptive operational environment. In each case, there were substantial demographic differences between cultural operators that were reduced when immersed in organizational learning cultures. Boostrom's (1994) scale supports a view of cultural adoption that occurs through graduated immersion, time and operational experience. The significance of this particular case may be found within the reciprocal relationships and willingness of the Founder to make learning a shared responsibility. Given the networks and background of the Founder, it would have been far easier for the Founder to be responsible for the growth and development mandates of the organization and task junior level employees with responsibility for implementation. A second and related point is that by distributing the responsibility for this core and centrally strategic function without prescribing the how, the new organization took more time to achieve growth objectives. However, I suggest this case has an exquisitely simple and important message for the creators of learning culture.

The creation of learning culture may take longer and be more difficult to achieve in the short term, but it will produce conditions of authentically embedded trust and psychological safety where an ethnically and demographically diverse working group may transcend individual differences in commitment to a culture of learning and doing. Again, it may seem to take longer and be more difficult in the short-term, but this case demonstrated strong results in the medium and long-term. A central question in creating learning culture is whether or not leadership is composed and mature enough to resist prescribing how. The principled leadership challenge in creating learning culture is trusting that shared learning and the co-creation of knowledge will construct better organizations. This case suggests that learning cultures will gain traction more easily when leadership is able to manage and mediate external threats and distractions from the operating environment. Achieving psychological safety and the expectation of performance are not mutually exclusive, and this case suggests they are achievable through principled leadership, and a dynamic and committed learning culture.

\section{References}

Argyris, C. (1959). The individual and organization: Some problems of mutual adjustment. Administrative Science Quarterly, 2, 1-24.

Bates, R. J. (1982, March). Towards a critical practice of educational administration. Paper session presented at Annual Meeting of the American Educational Research Association, New York, NY.

Biklen, S., Marshall, C., \& Pollard, D. (2008). Experiencing Second-Wave Feminism in the USA. Discourse: Studies in the Cultural Politics of Education, 29(4), 451-469. Retrieved from EBSCOhost.

Boostrom, R. (1994). Learning to pay attention. Qualitative Studies in Education, 7(1), 51-64. http://dx.doi.org/ 10.1080/0951839940070104 
Crotty, M. (1998). The foundations of social research: Meaning and perspective in the research process. London: Sage.

Greenfield, T. B. (1979). Organization theory as ideology. Curriculum Inquiry, 9(2), 97-112. Retrieved from EBSCOhost.

Greenfield, T. B. (1980). The man who comes back through the door in the wall: Discovering truth, discovering self, discovering organizations. Educational Administration Quarterly, 16(3), $26-59$. http://dx.doi.org/10.1177/0013161X8001600305

Kincheloe, J. L. (2004). Into the great wide open: Introducing critical thinking. In J. L. Kincheloe \& D. Weil (Eds.), Critical thinking and learning (pp. 1-52). Westport, CT: Greenwood Press.

Levin, B. (2008). How to change 5000 schools: A practical and positive approach for leading change at every level. Cambridge, MA: Harvard Education Press.

Merriam, S. B. (1998). Qualitative research and case study applications in education. San Francisco, CA: Jossey-Bass Publishers.

Merriam, S. B. (2002). Qualitative research in practice. San Francisco, CA: Jossey-Bass Publishers.

Packer, M. J., \& Addison, R. B. (1989). Evaluating an Interpretive Account. In M. J. Packer \& R. B. Addison (Eds.), Entering the circle: Hermeneutic investigation in psychology (pp. 274-321). Albany, NY: State University of New York Press.

Schein, E. H. (1999). The corporate culture survival guide. San Francisco, CA: Jossey-Bass Publishers.

Schein, E. H. (2009). Helping: How to offer, give, and receive help. San Francisco, CA: Berrett-Koehler Publishers.

Schein, E. H. (2010). Organizational culture and leadership. San Francisco, CA: Jossey-Bass Publishers. 